\title{
DESIGN PROCESS STABILITY: OBSERVATIONS OF BATCH SIZE, THROUGHPUT TIME AND RELIABILITY IN DESIGN
}

\author{
Eelon Lappalainen ${ }^{1}$, Petteri Uusitalo², Olli Seppänen ${ }^{3}$, and Antti Peltokorpi ${ }^{4}$
}

\begin{abstract}
Despite recent developments in construction design management, too much variability still occurs in design processes. Batch size (BS) and throughput time (TT) reduction are recurring concepts in the lean construction literature related to the Last Planner@ System (LPS). These three parameters are often used to reduce variability and improve flow and reliability in work processes. Some have attempted to reduce design variability through lean design management (LDM) and agile methods, but very few studies have analysed the interaction of these parameters in the design process. The purpose of this study is to investigate these variables and their interactions. Design process stability and reliability were measured over nearly two years in this study by using three parameters. According to the results, design teams with smaller BS's of design tasks and higher percentages of planned tasks completed also had shorter design task TT's. Designers may use these findings to improve their workflow monitoring and as a novel addition to LDM and coordination metrics.
\end{abstract}

\section{KEYWORDS}

Lean construction, Last Planner® System, agile, design.

\section{INTRODUCTION}

Because poor management and design process inefficiency often lead to construction project delays and cost overruns, design process management is a key factor in successful project delivery (Tilley, P. 2005a). Low reliability levels and high levels of variability in TT's cause problems for design stability and negatively affect the construction process (Khan and Tzortzopoulos 2014). Design could be said to be a bottleneck in the construction process (Tribelsky \& Sacks 2011). Bottlenecked processes with low reliability levels and high variability in delivery times inevitably mean that contractors must prepare contingency plans and demand earlier delivery times from designers. Such

1 Doctoral Candidate, Department of Civil Engineering, Aalto University, Finland, eelon.lappalainen@aalto.fi, orcid.org/0000-0002-7573-344X

2 Doctoral Candidate, Department of Civil Engineering, Aalto University, Finland, petteri.uusitalo@aalto.fi, orcid.org/0000-0002-7230-0788

3 Associate Professor, Department of Civil Engineering, Aalto University, Finland, olli.seppanen@aalto.fi, orcid.org/0000-0002-2008-5924

4 Assistant Professor, Department of Civil Engineering, Aalto University, Finland, antti.peltokorpi@ aalto.fi, orcid.org/0000-0002-7939-6612 
situations then reduce the time reserved for design work and ultimately lead to a vicious cycle in which even earlier design delivery and larger BS's in designs are required (Ballard \& Howell 1995). These scheduling buffers between stakeholders can protect contractors from the effects of delay but are often costly due to the extended construction times involved (Kenley \& Seppänen 2010).

A growing body of literature recognises the need to improve the flow of design processes (Ballard 2001; Sacks \& Goldin 2007; Hamzeh et al. 2009; Uusitalo et al. 2017). Many scholars have provided concepts for adapting agile methods, from software development to the design phase of construction projects (Koskela \& Howell 2002; Owen et al. 2006). Some engineering companies have implemented these methods as part of their processes (Streule et al. 2016; Føreland \& Halvorsen 2018; Uusitalo et al. 2017). The focus of several lean design methods and tools is to improve information flow among the design team, with the hope of lower design process variability (Uusitalo et al. 2019; Tribelsky \& Sacks 2011).

Although production is often controlled by adjusting BS and measuring the TT of process phases and process reliability (Hopp \& Spearman 2011), the concepts of BS, lead time and design process stability and reliability are typically limited in traditional construction design and design management. Instead, designers focus on implementing traditional project management methods, optimising sub-processes and cutting costs (Tilley 2005b). According to lean principles, process flow is a prerequisite for value creation (Bertelsen \& Koskela 2004) and the utilisation of indicators that will affect process flow and stability in design control and management. The goal is to achieve a more reliable design process.

Previous studies (Alarcón et al. 2008; Baladrón \& Alarcón 2017) have examined the relationship between process stability and PPC. The authors observed a relationship between high PPC and the stability of construction and mining processes. As PPC increased, the process was noted to stabilise accordingly. In these studies, the coefficient of variation $(\mathrm{CV})$ was used as a measure of process stability, calculated by dividing the standard deviation (SD) by the mean. Hopp and Spearman (2011) divided process variability into three categories: (1) low variability $(\mathrm{CV}<0.75$; process times without outages), (2) moderate variability $(0.75<\mathrm{CV}<1.33$; process times with short adjustments) and (3) high variability (CV > 1.33; process times with long outages). Alarcón et al. (2008) showed that with the increase of PPC, the production process was stabilised by up to 30 $40 \%$ as measured by CV.

Clearly, the pre-production process (i.e. design) must also be stable and predictable. Although several design-related studies of PPC have been published, very few are related to BS and TT in design. Similarly, very few studies have measured the stability of the design process using $\mathrm{CV}$. The purpose of this empirical study was to examine connections between BS, TT and PPC in design process by using a single case study consisting of seven construction sites in Finland.

\section{RESEARCH DATA AND METHODS}

The research data used in this paper was gathered from a single case study consisting of seven construction sites. The sites are located in Finland and pertain to a client-driven subway project consisting of five stations, one depot and a railway line connecting them, with its own design teams consisting of different design disciplines. Six of the construction sites used agile methods and the Last Planner® System (LPS) among the structural design teams, while the one remaining site was managed with traditional 
methods, and thus research data was not available for that site. The agile method known as "Scrum" was introduced for the first time in this project and involved 156 structural engineers from several structural engineering companies that operate in the Nordic countries. The structural engineers worked on the project as teams of 15 to 25 people. After a short orientation period, the structural engineering work was broken down to a workable backlog of design tasks, for which task-specific responsible persons were appointed. These tasks were pulled from the backlog into the two-week design periods called "sprints." The progress of the work was monitored over a two-year period using Jira software, where design tasks were managed based on Scrum principles. The software provided a chart of work progress as well as progress projections of the design work. After the orientation phase, which was done in physical space, latter bi-weekly meetings were held in virtual space, with teleconference tools. Structural designers worked with other disciplines, such as architects and MEP designers, in coordination meetings.

All sites had their own design managers (DM), but structural design was centrally coordinated by one DM, who was responsible for structural design coordination, created biweekly status reports of the design progress. These reports included design progress, projections and possible problems or resource shortfalls that could lead to the client's control actions, if necessary. The information also provided data on the development of TT and PPC for design tasks, which were addressed in retrospectives with design teams. For this study, the data we collected was exported to Microsoft Excel and statistical analysis program Minitab 19.0, which we used to sort and analyse the data with functions as well as to generate tables and graphs.

The main data used in this study contains the designers' workload estimates for design tasks, PPC values (measured biweekly during the design phase) and measured TT's for design tasks. Workload estimate data was stored during the project on the task cards included in the programme. The programme calculations were based on workload estimates, such as forecasts for the completion of the remaining work. For the purpose of this study, these task-specific workload estimates were then exported from the software to an Excel spreadsheet. PPC values were calculated using sprint reports generated by the programme by calculating completed and non-completed tasks during the sprint and dividing their ratio by the PPC percentage. TT's were calculated to the accuracy of one sprint (i.e. whether the design task was completed during one or more two-week sprints). This data was then transferred to an Excel spreadsheet, in chronological order. Workload estimates were measured in hours per task, PPC values were measured as percentages and design task TT's were measured as two-week work periods (sprints $\mathrm{nr} 1, \mathrm{nr} 2, \mathrm{nr} 3$, etc.). Minitab was utilised to perform an analysis of variance (ANOVA) for TT's, using oneway ANOVA as the statistical method.

\section{RESULTS}

The results are presented in three sections according to the collected data: observations of (1) BS, (2) TT and (3) PPC values. We will first focus on the BS results. The data analysis showed that the use of the agile method, with a sprint length of two weeks and a maximum workload estimate of one week, guided the division of design tasks towards the desired BS, which in this context was a maximum of one work week (40 hours). Figure 1 shows the average BS's of the design tasks for the two-year follow-up period; the upper limit of the target BS is shown. As the figure makes apparent, only one site exceeded the target-specific maximum number of hours per task in the first year; in the 
second year, all sites fell below the target, and half the sites remained at less than 20 hours per planning task.

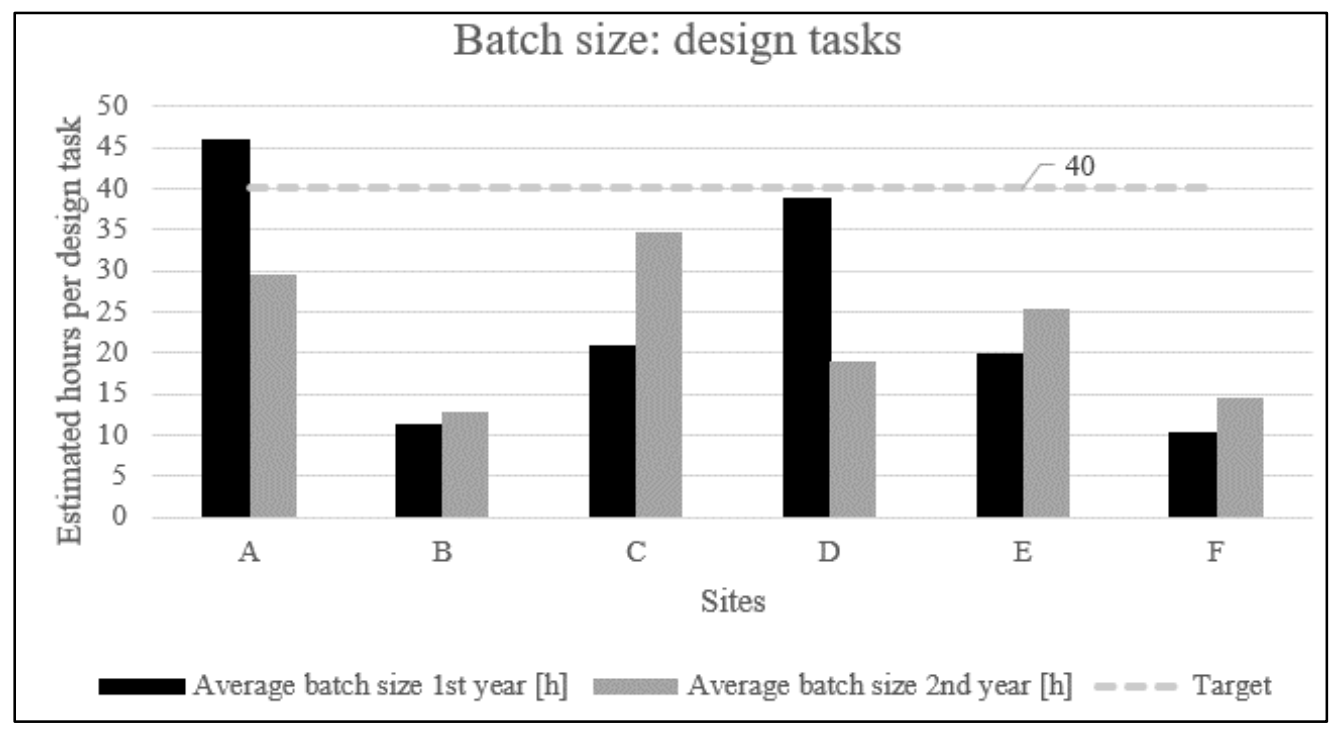

Figure 1: Estimated BS's of design tasks

Because the results are workload estimates, we also examined the relationship between the estimated working hours and the actual, invoiced working hours during the monitoring period. The estimated workload estimates of the design tasks varied from 1.5 to 3 times higher during the measurement period, meaning the working hour estimates in relation to the actual hours were overestimated. In discussions with designers, some of them noted experiencing challenges in providing workload estimates; the results suggest that task-specific workloads include significant capacity buffers.

Another part of the results included observations of TT's. As Figure 2 shows, sites E and F clearly differed from the other sites by having faster task TT's. Sites C and D had the longest TT's while sites A and B and were located between the two groups.

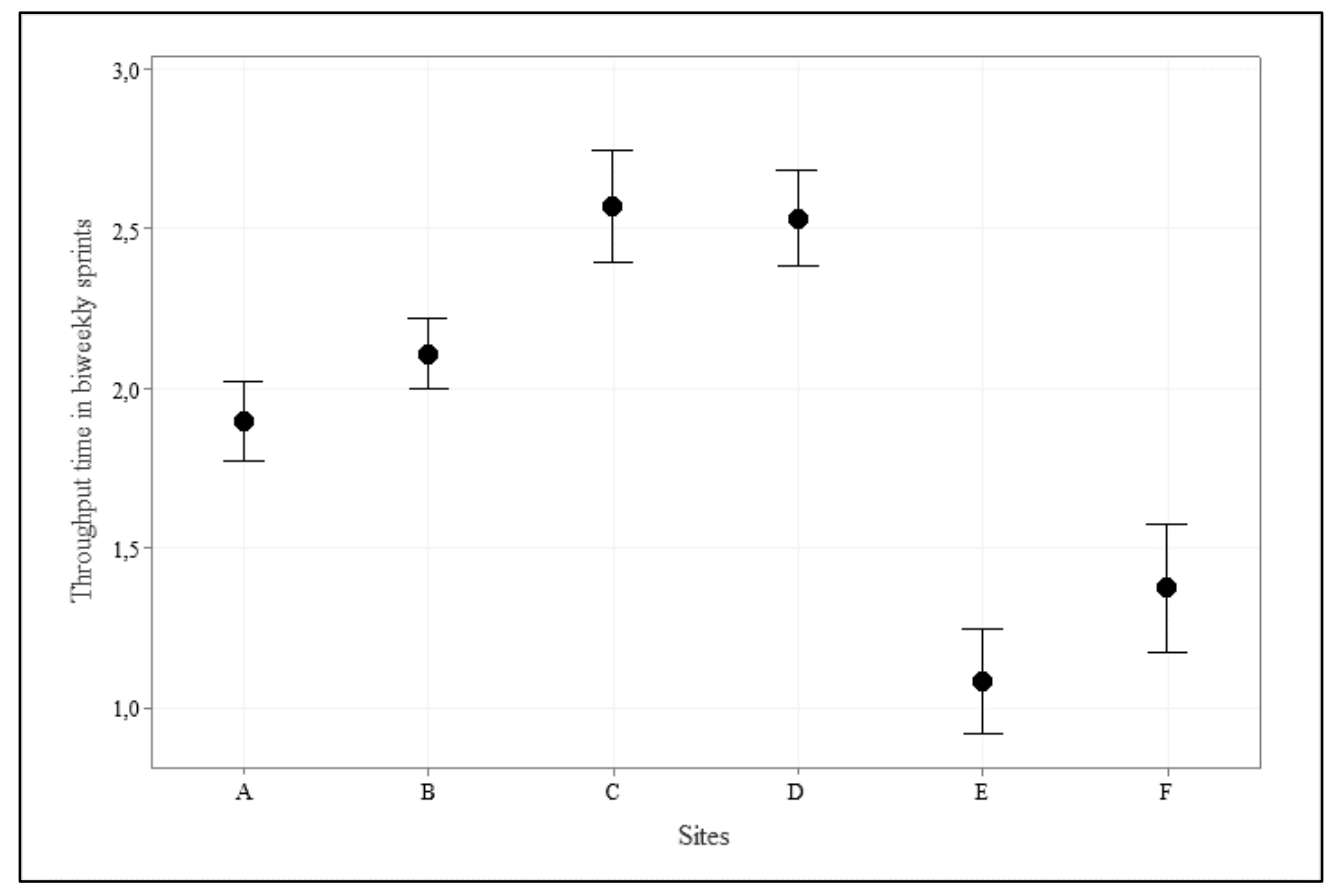

Figure 2: Analysis of variance, interval plot of TT in years 1 and 2. 
For the TT, we noted a statistically significant difference in the results of sites $\mathrm{E}$ and $\mathrm{F}$ (group 1), sites A and B (group 2) and sites C and D (group 3). This difference also appeared in an interesting way in the analysis of PPC values, as discussed below.

Table 1 is grouped into three segments: (1) plan reliability, which is described by data related to PPC values; (2) BS; and (3) the stability of the design process, which is described by the CV value of the design process. As shown in Table 1, all sites improved PPC levels during the follow-up period, but for PPC variability, only half the sites saw reduced PPC variability during the follow-up period. For BS, only two sites saw BS reduction during the follow-up period. Four sites managed to improve their $\mathrm{CV}$ during the follow-up period.

Table 1: Summary table of key metrics. $\mathrm{PPC}=$ planned percentage completed, $\mathrm{SD}=$ standard deviation, $\mathrm{CV}=$ coefficient of variance, $\mathrm{LV}=$ low variability, $\mathrm{MV}=$ moderate variability and $\mathrm{HV}=$ high variability

\begin{tabular}{|c|c|c|c|c|c|c|c|c|c|c|}
\hline \multirow[b]{2}{*}{ Site } & \multicolumn{4}{|c|}{ Reliability } & \multicolumn{4}{|c|}{ BS's in design tasks } & \multicolumn{2}{|c|}{ Stability of design process } \\
\hline & $\begin{array}{l}\text { PPC } \\
\text { ave. } \\
\text { of } 1 \text { st } \\
\text { year }\end{array}$ & $\begin{array}{c}\text { PPC } \\
\text { ave. } \\
\text { of } \\
\text { 2nd } \\
\text { year }\end{array}$ & $\begin{array}{c}\text { SD of } \\
\text { PPC } \\
1 \mathrm{st} \\
\text { year }\end{array}$ & $\begin{array}{l}\text { SD of } \\
\text { PPC } \\
\text { 2nd } \\
\text { year }\end{array}$ & $\begin{array}{c}\text { Ave. } \\
\text { BS } \\
1 \mathrm{st} \\
\text { year } \\
{[\mathrm{h}]}\end{array}$ & $\begin{array}{c}\text { Ave. } \\
\text { BS } \\
\text { 2nd } \\
\text { year } \\
{[\mathrm{h}]}\end{array}$ & $\begin{array}{c}\text { SD in } \\
\text { BS } \\
1 \text { st } \\
\text { year }\end{array}$ & $\begin{array}{l}S D \text { in } \\
\text { BS } \\
\text { 2nd } \\
\text { year }\end{array}$ & $\begin{array}{c}C V \\
\text { 1st year }\end{array}$ & $\begin{array}{c}\mathrm{CV} \\
\text { 2nd year }\end{array}$ \\
\hline A & 38.2 & 56.1 & 37.2 & 23.3 & 45.9 & 29.4 & 88.8 & 46.2 & $\begin{array}{l}1.93 \\
(\mathrm{HV})\end{array}$ & $\begin{array}{l}1.57 \\
(\mathrm{HV})\end{array}$ \\
\hline B & 26.5 & 58.9 & 26.2 & 24.6 & 11.2 & 12.9 & 12.4 & 8.2 & $\begin{array}{l}1.11 \\
(\mathrm{MV})\end{array}$ & $\begin{array}{l}0.64 \\
\text { (LV) }\end{array}$ \\
\hline C & 13.3 & 52.2 & 14.8 & 22.3 & 20.8 & 34.6 & 13.8 & 32.4 & $\begin{array}{l}0.66 \\
\text { (LV) }\end{array}$ & $\begin{array}{l}0.94 \\
\text { (MV) }\end{array}$ \\
\hline $\mathrm{D}$ & 24.0 & 51.9 & 26.4 & 24.1 & 38.8 & 19.0 & 59.7 & 26.8 & $\begin{array}{l}1.54 \\
\text { (MV) }\end{array}$ & $\begin{array}{l}1.41 \\
(\mathrm{HV})\end{array}$ \\
\hline$E$ & 37.7 & 71.2 & 36.1 & 14.2 & 19.7 & 25.4 & 13.4 & 27.2 & $\begin{array}{l}0.68 \\
\text { (LV) }\end{array}$ & $\begin{array}{l}1.07 \\
\text { (MV) }\end{array}$ \\
\hline $\mathrm{F}$ & 35.3 & 71.3 & 32.4 & 19.0 & 10.3 & 14.4 & 94.8 & 11.7 & $\begin{array}{l}9.20 \\
(\mathrm{HV})\end{array}$ & $\begin{array}{l}0.81 \\
\text { (MV) }\end{array}$ \\
\hline
\end{tabular}

All sites met their BS targets during the second year, and three sites halved their BS targets. CV also fell, except at two sites (C and E), although CV was at a moderate level in these two sites. In site F, the high HV was due to difficulties in using the new method at the beginning of the first monitoring year and the use of very low task-specific workload estimates, which led to a large variance from the workload forecasts for the rest of the year. This data has not been removed or modified, however, because it contributes to an understanding of the challenges of implementing agile methods in design.

In summary, these results show that sites $\mathrm{E}$ and $\mathrm{F}$ differed from other sites with higher PPC numbers and clearly different faster TT's. Correspondingly, sites C and D, where PPC was lowest, also had the highest TT's. In workload estimates (i.e. BS), differences between the sites were not so clear. Sites B and F were clearly lower than the other sites in both years, while for C and E BS increased in the second year. Sites A and D managed to improve BS in their second year. However, sites $\mathrm{E}$ and $\mathrm{F}$ were evidently in low level in BS and TT as well in high level in PPC. 


\section{DISCUSSION}

In this study, we set out to assess the importance of design process stability and reliability by comparing three key parameters: (1) BS, (2) TT and (3) PPC level. A comparison of the findings with those of previous studies confirmed the positive effect of PPC on process stability in design processes (Alarcón et al. 2008; Baladrón \& Alarcón 2017). These results also corroborate the findings of previous work by El-Samad et al. (2017), who suggested that new metrics should be developed for LPS. However, research on these metrics has been limited so far because teams often do not adequately document their results, making the results unverifiable. Fortunately, in this study, the design teams documentation was comprehensive due to the agile task management system (TMS) they used, which allowed data to be analysed with different metrics. The results are also consistent with those of Tribelsky and Sacks (2011), who showed how BS's, bottlenecks and other obstacles of flow in the design process can be measured from a project's data management system (DMS). Based on our results and those of previous studies, we encourage further research to focus on combining data from LPS, DMS and task management tools such as Jira and to use the data to create a holistic view of the stability of the design process.

Despite the small number of sites we examined for this study, the findings are encouraging. Connections could indeed exist between BS, TT and PPC level. Despite these findings relate to each other, PPC levels were low in these sites, and these results therefore must be interpreted with caution. One factor that may have contributed to the low PPC values was the lack of daily management. For comparison, Streule et al. (2016) presented how the performance of the design team examined in their study improved within 27 days through day-to-day management. We have noted similar preliminary findings in our current research, in which daily management quickly and permanently raises PPC levels in design.

The amount of work in progress (WIP) was not limited during the design work in the case study. The impact of this situation was especially evident during the first year, when the designers became accustomed to using the Scrum method. The lack of WIP limits may also have limited the increase of PPC to a higher level than was currently the case. We will continue to explore this relationship as the study progresses.

Discussions with the designers revealed that despite the challenges they reported in evaluating workload estimates, the task-specific workload forecasts were significantly buffered. We checked this claim by comparing the ratio of workload forecasts to actual invoiced hours worked. Researchers have made similar observations on the production side (e.g. Kala et al. 2012), and design and production actors seem to have similar ways of building a safety buffer for their planned tasks. This finding raises the question of whether bottlenecks in design tasks could be identified by combining DMS data and TMS data (Tribelsky \& Sacks 2011). According to the general concept of bottlenecks, a buffer accumulates in front of the process bottleneck (Goldratt, 1990). For future research, we propose to identify tasks or task groups where the planned and actual workloads differ significantly as the design progresses and to focus on broadening factors of these bottlenecks, for example through root cause analysis.

In design, as in other processes, the different steps of the process follow each other, partly iteratively. Uusitalo et al. (2019) have presented the significance of BS and the related results, for example regarding the inspection of design documents, which is the end point of the design process. Our observation of decreased BS's in relation to increased design reliability and reduced throughput raises intriguing questions for the developers of 
design management processes. When interpreting the results, readers should keep in mind that the relationships we observed do not explain how the factors interact with each other, and we cannot say with certainty whether, for example, a small BS leads to a short TT and thus higher PPC. Or compliance to planned TT leads more likely to a higher PPC. Evidence of a causal relationship will require future research using different methods.

\section{CONCLUSIONS}

This paper contributes to previous research by presenting the interrelations between design process stability and reliability through a case study and by using three parameters, BS, TT and PPC.. Based on this study's results, this interrelation seems to exist in design work. This observation opens several new questions for future research. For example, regarding BS, the key question is to discover the optimal BS for different design phases and disciplines. Similarly, further research is needed on different types of projects: for example, whether the connection we found in this case study would be similar, regardless of the design target. By combining PPC, task TT's and BS tracking of design tasks, researchers can potentially create new perspectives on more reliable and stabile design processes. Perhaps the most topical question for further research is how a production method based on small BS, such as takt production, affects design BS's and TT's. Unfortunately, our study did not include other design disciplines or other design phases, where interrelations may not be similar, which would require more research data. The findings of this study have raised a number of practical implications in construction design management. First, this study's findings suggest that, in addition to PPC monitoring alone, taking advantage of the TT's and BS measurements provided by task management tools to monitor the design process can provide a new perspective on the design process and the flow of design work. Second, this study demonstrates how differences between design teams can be measured by relatively simple methods and with existing digital tools and how digitally collected information can be used to solve the problem of design inefficiency.

\section{REFERENCES}

Alarcón, L.F., Diethelm, S., Rojo, O. and Calderón, R. (2008). "Assessing the Impacts of Implementing Lean Construction.” Revista Ingeniería de Construcción, 23(1), 26-33.

Baladrón, C. and Alarcón, L.F. (2017). "Assessing the Impact of Lean Methods in Mining Development Projects.” In Proc., 25th Ann. Conf. IGLC (pp. 137-144). Budapest, Hungary: IGLC.

Ballard, G. (2001, August). "Cycle Time Reduction in Home Building." In Proc., 9th Ann. Conf. IGLC (pp. 06-08). Singapore: IGLC.

Ballard, G., \& Howell, G. (1995). Toward construction JIT. Lean construction, 291, 300.

Bertelsen, S. and Koskela, L. (2004, August). "Construction beyond Lean: A New Understanding of Construction Management." In Proc., 12th Ann. Conf. IGLC (pp. 02-05). Helsingor, Denmark: IGLC.

El-Samad, G., Hamzeh, F. and Emdanat, S. (2017, July). "Last Planner System: The Need for New Metrics." In Proc., 25th Ann. Conf. IGLC (pp. 637-644). Budapest, Hungary: IGLC.

Føreland, J.A. and Halvorsen, A.B. (2018). Managing Change When Implementing a New Project Management Methodology: A Constructive Approach to Change Management. Master's Thesis, University of Agder. 
Goldratt, E.M. (1990). Theory of Constraints (pp. 1-159). North River, Croton-onHudson, N.Y.

Hamzeh, F.R., Ballard, G. and Tommelein, I.D. (2009, July). "Is the Last Planner System Applicable to Design? A Case Study." In Proc., 17th Ann. Conf. IGLC (vol. 17, pp. 13-19). IGLC: Taipei, Taiwan.

Hopp, W.J. and Spearman, M.L. (2011). Factory Physics. Waveland Press, Long Grove, IL (pp. 268-271).

Kala, T., Mouflard, C., \& Seppänen, O. (2012, December). Production control using location-based management system on a hospital construction project. In 20th Annual Conference of the International Group for Lean Construction, San Diego, California, USA (p. 039).

Kenley, R. \& Seppänen, O. (2010). Location-Based Management for Construction. CRC Press. Kindle Edition. p. 4764.

Khan, S., \& Tzortzopoulos, P. (2014, June). Effects of the interactions between LPS and BIM on workflow in two building design projects. In 22nd Annual Conference of the International Group for Lean Construction. Oslo, Norway, 25-27 Jun 2014. (Vol. 2, pp. 933-944). IGLC and Akademika forlag.

Koskela, L. and Howell, G. (2002, August). "The Theory of Project Management: Explanation to Novel Methods." In Proc., 10th Ann. Conf. IGLC. (vol. 10, no. 1, pp. 1-11). Gramado, Brazil: IGLC.

Owen, R., Koskela, L., Henrich, G. and Codinhoto, R. (2006). "Is Agile Project Management Applicable to Construction?" Proc., 14th Ann. Conf. IGLC. Santiago, Chile: IGLC.

Sacks, R. and Goldin, M. (2007). "Lean Management Model for Construction of HighRise Apartment Buildings.” J. Const. Eng. Man., 133(5), 374-384.

Streule, T., Miserini, N., Bartlomé, O., Klippel, M. and De Soto, B.G. (2016). "Implementation of Scrum in the Construction Industry." Proc. Eng., 164, 269-276.

Tilley, P. A. (2005a March). Design and Documentation Quality Problems-A Lean Thinking Opportunity. In Proceedings of the International SCRI Symposium, Salford, UK (pp. 12-13).

Tilley, P.A. (2005b July). "Lean Design Management: A New Paradigm for Managing the Design and Documentation Process to Improve Quality?" Proc., 13th Ann. Conf. $I G L C$ (p. 283). Sydney, Australia: IGLC.

Tribelsky, E. and Sacks, R. (2011). "An Empirical Study of Information Flows in Multidisciplinary Civil Engineering Design Teams Using Lean Measures.” Arch. Eng. Des. Man., 7(2), 85-101.

Uusitalo, P., Olivieri, H., Seppänen, O., Pikas, E. and Peltokorpi, A. (2017, July). "Review of Lean Design Management: Processes, Methods and Technologies." In Proc., 25th Ann. Conf. IGLC (pp. 571-578). Heraklion, Greece: IGLC.

Uusitalo, P., Seppänen, O., Lappalainen, E., Peltokorpi, A. and Olivieri, H. (2019). "Applying Level of Detail in a BIM-Based Project: An Overall Process for Lean Design Management.” Buildings, 9(5), 109. 